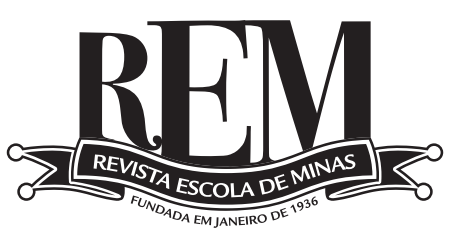

Afiliada à

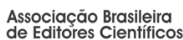

A B E C

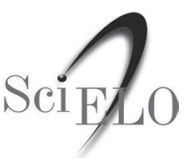

THOMSON REUTERS

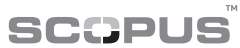

Geoscience $_{\text {als }}$

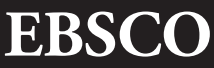

P U B L I S H I N G

Provider of EBSCOhost ${ }^{\circ}$

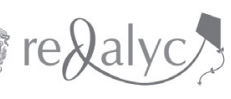

http://dx.doi.org/10.1590/0370-44672018710010

\section{Upgrade or perish}

"Life is like riding a bicycle. To keep your balance, you must keep moving."

Albert Einstein.

Letter to his son Eduard (February 5,1920), as cited by Walter Issacson in Einstein: His Life and Universe (2007), page 367.

I believe that the affirmation above can be adapted to various situations, including scientific magazines that need to maintain "in movement", in order to maintain the fidelity of their readers.

It was in thinking of the "movement" that some measures are being implanted in 2018. Conquering the first barriers of IT, REM adopted the ScholarOne system, amplified with the use of plagiarism detection with the iThenticate software, that is, the analysis by the Plagiarism CrossRef Software (iThenticate) that lets us compare documents to the vast database of content for plagiarism and attribution using the most comprehensive plagiarism checker technology.

Although ScholarOne permits the authors to indicate possible Reviewers, many have indicated whomever without worrying about the Reviewer's knowledge of the subject involved, and many times, this false indication compels many of the associated editors (principally those abroad) to delay the article's analysis. This observation has led REM to take action to ensure the principal finality of the permission: to increase the number of these Reviewers from 2 to 4, being mandatory that the authors justify their indication of the Reviewers.

Another problem that exists is the analysis by pairs, who sometimes demonstrate little interest and only superficially evaluate the article. A new version of ScholarOne, with adoption of Risk Indicator will closely accompany this article. Unusual activity detection identifies unusual activity by users during submission and review. Journals will see a risk indicator on the manuscript header. The risk indicator is derived from using proprietary algorithms based on existing web traffic and server data such as when Reviewers are suggested by the Author and when Reviewers use a non-institutional email address, etc.

Another decision made was to terminate the printed edition of REM. Upon adopting the Open Access system in 2001, it was evident that the number of subscribers would diminish with time. The increase in printing expenses, post office, together with the free online access of the articles has made the price of the printed issues exorbitant. We plan to create an applicative so that readers can consult the articles in the normal devices available at the present.

With the certainty that REM with its eighty two years of existence will continue to maintain its goal of expanding worldwide, our team thanks the support everyone has given REM in 2017. We hope that the new measures implanted, along with new financial resources for increasing the disclosure of good scientific articles, will not only have a positive impact in 2018, as well as make it possible for You to improve your research because of REM.

Best Regards

Prof. Jório Coelho
Editor-in-Chef
Doctor Engineer by Polytecnique Institute of Lorraine-France
Retired professor of Federal University of Ouro Preto - School of Mines-Department of Geology
E-mail: editor@rem.com.br
$35400-000$ - Ouro Preto - BR

References

ISSACSON, W. in Einstein: His Life and Universe 2007, p. 367. 